\title{
The Ethics of Students' Behavior: Between Intentions, Judgment and Action
}

\author{
Adela Coman ${ }^{1}$, Virginica Rusu ${ }^{2}$ and Valentin Mihai Leoveanu ${ }^{3}$ \\ 1,3 University of Bucharest, Bucharest, Romania \\ ${ }^{2}$ University of Playa Ancha, Valparaiso, Chile
}

Correspondence should be addressed to: Adela Coman; adela_coman2003@yahoo.com

Received date: 9 August 2016; Accepted date: 14 December 2016; Published date: 14 February 2017

Academic Editor: František Milichovský

Copyright (C) 2017. Adela Coman, Virginica Rusu and Valentin Mihai Leoveanu. Distributed under Creative Commons CC-BY 4.0

\begin{abstract}
Consumption behavior - not long ago a neglected and marginalized domain -has shifted its focus towards exploring questionable ethical behaviors. While in the past consumers were questioned especially with regard to their opinions as to business ethics, today they are questioned as to the ethics of their consumption behavior. This study focuses upon the possible explanations of ethically questionable consumer behavior, namely the ethics of students' behavior from a comparative perspective: the students from the Faculties of Business and Faculties of Medicine from Romania and Bulgaria. Our results indicate the fact that there are no significant differences as to the ethical buying behavior between the two groups of students from the two countries. Moreover, there are no significant differences between the students of the two approached majors in Romania and Bulgaria in terms of knowledge and information related to ethical/non-ethical conduct. Despite all this, our research proves that when faced with real shopping situations, most students have the tendency of acting unethically, using different types of pretexts ("super-stories") in order to justify their "sideslip" from the declared behavior. This mismatch between the declared behavior (intention to buy ethically) and the real behavior (action) can be explained by means of social factors (situational conditions). In our case, theoretical education, information and the students' efforts to behave ethically as consumers seem to be highly undermined by the realities of the standard of living, expressed through their families' level of income. In other words, behavioral intentions are affected by ethical judgments: when given the opportunity, students make judgments: perceived unfairness, though context specific, show signs of significant influence on the practice of unethical behavior.
\end{abstract}

Keywords: the ethics of consumer behavior, super-stories, family income

Cite this Article as: Adela Coman, Virginica Rusu and Valentin Mihai Leoveanu (2017), " The Ethics of Students' Behavior: Between Intentions, Judgment and Action ", Journal of Marketing Research and Case Studies, Vol. 2017 (2017), Article ID 246481, DOI: 10.5171/2017.246481 


\section{Introduction}

Hunt and Vitell's general theory of marketing ethics $(1986,1992)$ and Ajzen's theory of planned behavior $(1985,1991)$ are the most important theoretical approaches applied to the field of consumers' ethical decisionmaking. Both authors base their models on the premise that ethical attitudes are consistent with intentions in most cases. According to Fukukawa (2002), similarities are more important than differences between the two (attitudes and intentions). Hunt and Vitell $(1986,1992)$ show that the ethical decision process starts when the consumer perceives himself/herself as having an ethical problem. As a result, he/she makes an evaluation of the situation, arrives at a judgment which in turn, influences the consumer's behavioral intentions. More often than not, evaluations affect intentions indirectly (through ethical judgments), but also directly. That is, consumers may not choose the best (ethical) alternative due to the desirable consequences of a less ethical one.

Furthermore, intention may differ from actual behavior due to contextual factors enabling consumers to engage in unethical behavior. In the end, the consequences of buying unethically become part of the consumer's learning experience and, in this case, it may generate feelings of guilt that will affect future behavior.

Ethical consumption is largely approached both in the written media and in academic reviews (Crane \& Matten, 2004; Vitell \& Muncy, 1992). Aspects such as using child labor in developing countries or the impact of production and consumption upon the environment seem to affect the buying decisions process of consumers throughout the world (Auger et. al., 2003; Creyer \& Ross, 1997; Elliott \& Freeman, 2001). This change in the behavior of consumers has profound implications for the managers and may influence their decisions as regards the choice of a location for their production facilities, the human resources policies within the company and the role of ethical corporate business practices.

Despite the ever increased attention for issues related to ethical consumption during the past years, the data regarding its importance are at best contradictory. For example a study undertaken by Market \& Opinion Research International (MORI) shows that over one third of the British consumers were concerned about ethical issues (Mason, 2000). The same study suggests that the potential for ethical products in the UK could be of $30 \%$ of the market of staple products. Another study undertaken by Corporate Edge shows even more attention and importance given to ethical behavior in the sense that $57 \%$ of consumers state that they would no longer buy a product if they knew that that product was done by children or women, under improper conditions (Rogers, 1998).

On the other hand, other researchers suggested that the consumers' opinions do not seem to be translated into a change of their buying behavior (Carrigan \& Attala, 2001). This suggests the fact that there seems to be some incongruity between what consumers say as regards the importance of the ethical issues and what they do when they are in a shop. This incongruity determined certain researchers to believe that research of the ethical consumption is not reliable (Ulrich \& Sarasin, 1995).

These issues even made certain researchers suggest that it might be opportune to take into consideration this incongruity between attitude and behavior - an incongruity with a high impact upon ethical and social issues which affect the buying decisions (Boulstridge \& Carrigan, 2000; Carrigan \& Attala, 2001; Simon, 1995; Ulrich \& Sarasin, 1995). In other words, consumers declare in market surveys that ethical and social issues are important but they do not change their buying behavior accordingly. 
The inconsistency between statement and deed seems to be particularly obvious amongst students, a social category which has always played an active role in the development of a society's consciousness related to such issues as environment protection or women and children exploitation in developing countries. As a consequence, several studies have been designed with the aim of deciphering their attitudes and behaviors as to issues that society considers sensitive. Moreover, the fact that students will be the ones who will manage and consume the current and the future resources of this planet was an efficient incentive for this type of research.

Some of these research studies have shown that direct economic consequences, such as paying a lower price when buying a product, influence the degree of tolerance in consumers, and in students in particular, as regards the equivocal behavior, arguable from an ethical perspective (Dodge, Edwards and Fullerton, 1996). A study undertaken by Bloch, Bush and Campbell (1993) showed that, generally, consumers will choose a counterfeit product over an original one when there is a price advantage in question. Even though counterfeit products compromise quality, consumers are willing to ignore this drawback as long as they save some money. This does not mean that all consumers buy counterfeit products but merely that amongst those who buy counterfeit products there exist differences as to the frequency of acquisitions and differences as to the importance or degree of satisfaction generated by the characteristics of the product, depending on the class of products to which it belongs (Gail, Garibaldi, Zeng, Pilcher, 1998).

Both consumers who buy counterfeit products consciously and those who do not buy them at all agree upon the fact that these cause damage to companies producing original products. Price is nevertheless of huge importance in the sales of counterfeit products. This is why consumers, when making decisions, weigh their financial gain on the one hand and the benefits they expect from the specific product on the other hand (O'Shaughnessy, 1987, McGregor, 2007).

\section{Literature Review}

Research studies regarding consumer ethics and ethical decision-making are few. Some authors empirically analyzed specific consumer behavior with ethical implications. The most researched domains are shoplifting (Kallis et al., 1986; Moschis \& Powell, 1986) and ecologic consumption (Antil, 1984; Haldeman et al., 1987). Other authors focused on behavior codes dealing with ethics issues, needed by consumers and businessmen. For example, Stampfl (1979) developed a code of ethics for consumers, while Schubert (1979) described a number of strategies useful in preventing the abuse that sometimes consumers face in the marketplace.

Other authors created a conceptual and empirical basis for the understanding of the consumer decision making process. Thus Grove et al, (1989) designed a model based on the neutralization techniques developed in sociology by Sykes and Matza (1987) who helps us understand the way people justify their unethical behavior. Amongst these techniques we can mention: not assuming responsibility, not accepting the existence of any damage, not admitting the existence of a certain victim or the appeal to superior loyalties. Given the scarcity of research in this domain, the neutralization techniques seem able to shed some light upon the study of the ethical consumption behavior.

In the literature dedicated to this issue there exist three empirical studies which analyze the consumer's ethical rationalizations. The first is Davis' study (1979), who analyzes to what extent people are willing to assume responsibility, in relation to the rights they have as consumers. The study shows that individuals are bound to claim their rights as consumers rather than assume the responsibility incurred. More specifically, $95 \%$ of the individuals accept the rights, 
while only $74 \%$ accept the incurred responsibilities.

In a similar study, DePaulo (1987) researched the students' perceptions as regards the wrong buying behaviors. Some of the situations presented to the interviewed individuals referred to the shop-assistants' behavior and others focused on the consumers' behavior. Thus pairs of behaviors were created, which were conceptually similar, but which were different from the perspective of the individual engaged in an unethical behavior, namely the shopassistant or the buyer. According to Davis (1979), the interviewed individuals were more critical with respect to the shopassistant when these engaged into unethical behaviors, and less critical with respect to consumers when these engaged into the same kind of (unethical) behaviors.

Wilkes' study (1978) analyzes the rationalizations of consumers regarding the extent to which a certain type of behavior is considered "wrong" from their point of view. Despite the fact that there exist statistics regarding the unethical or fraudulent consumption behavior, Wilkes' study is the only one which analyzes the individuals' perceptions as regards these habits. Although certain fraudulent behaviors were condemned less than others, most of these activities were perceived as being "wrong". Relatively few behaviors were perceived as being acceptable /tolerable. These "points of tolerance" seem to be linked to those "blamable" behaviors in which the guilt is of the business environment rather than of the consumer.

The consumers' ethical decisions gain moral motivation especially when one considers that a consumer's actions carried out in total freedom affect the wellbeing of others (Izzo, 1997). The ethical issue gains in magnitude when the consumers' wrong/unethical decisions harm other people (Jones, 1991). But common people cannot become aware of such issues if they do not perceive consumption as having an imperative moral accent. Unless people incorporate moral ideals (honesty, equity, fairness) into their own identity, they will not feel tempted to perceive consumption as having a moral imperative (Moisander, 1998). This deficiency explains why people will not perceive themselves as being sensitive from an ethical point of view, capable of discerning at a moment when a certain issue requires the application of ethical principles and moral ideals. Practically, the moral imperative should become an integral part of their selection criteria (McShane \& Travaglione, 2005; McGregor, 2005).

In order that people should be able to make an ethical decision, they have to relate to a behavioral norm or rule that they can use as benchmark. Secondly, people have to be aware that their decision will affect others, whether employees, producers or consumers, sometimes with unexpected consequences. Thirdly, people have to accept and assume the responsibility for the moral issue and the prejudice they create (Schwartz, 1977).

If these conditions are not met, the idea of buying while assuming a certain moral conscience is compromised, because the absence of these conditions means that consumers are unable to recognize the moral side of their buying decisions. Cowe and Williams showed that only $17 \%$ of the interviewed consumers declared that they felt guilty when they purchased a product that did not meet the principles of ethics. In other words, $83 \%$ never felt guilty when they bought something without even considering the potential damage caused to others.

This observation can have profound implications. Research has shown that the moral intensity of a certain issue, correlated with the ethical intentions of a certain individual, influence the (ethical) decision making process. Ballantine (2000) cites 7 studies undertaken in the '90, all in support of this idea. 
Izzo (1997) also approached the issue of moral intensity within the buying decision. According to Izzo, moral intensity reflects the degree to which the consumer perceives the necessity of observing ethical principles when shopping. The perceived level of moral intensity affects that individual's evaluation of the ethical content of a certain buying situation. Izzo also states that while some buyers are very sensitive as to the buying decisions with ethical content, others must experience a shock before they react. This lack of sensitiveness is more likely to appear if the society did not assimilate a set of principles according to which ethical shopping represents the desired and expected behavior.

Next, we wanted to analyze the ethical behavior of students from Romania and Bulgaria. We were equally interested in the manner in which students define their own ethical behavior, using the answers provided in our questionnaire, and in the motivation that could determine them to make unethical decisions once they arrive in the shop.

\section{Objective of the Research}

Studies undertaken so far prove that, generally speaking, there exist differences in terms of behavior and ethical and/or unethical attitudes amongst the undergraduate students. Yet the aim of our study was to find out if, according to the things declared in surveys, there exist differences between the buying behaviors and attitudes of students matriculated in two different majors - Business and Medicine - in Romania and Bulgaria. On the other hand, we wanted to see if certain social and economical characteristics (such as the level of income of the families from which these students originate) affect in some way the ethical behavior declared (in surveys) as compared to the real behavior (in shops) of the students from the two countries. We are thus trying to explain the differences between declarative attitudes/behavior (intention) and the real behavior (action) of Romanian and Bulgarian students.
Thus, we tried to find answers to the following questions:

1. Are there any significant differences between the ethics of shopping for students in Romania and Bulgaria?

2. Is there any significant difference in the ethical behavior of students enrolled in different faculties?

3. Is there any difference in the buying behavior of the students due to differences related to the family income?

4. What are the main excuses/claims that students make in order to reconcile their behavior with their actions?

There is one thing worth mentioning as to the two countries approached in this study: in 2010 Romania and Bulgaria had the lowest GDP per capita in the European Union, by $55 \%$ below the average in the European bloc. The standard of living in Romania and Bulgaria dropped in 2010, the GDP per capita falling farther away from the European average (EUROSTAT, 2010). The two countries had the lowest standard of living in 2011 as well. In 2015, Bulgaria was the member-state with the lowest per capita GDP expressed in PPS, at $54 \%$ below the EU average. At short distance, Romania surpassed its neighbors in the south with a GDP per capita of less than $50 \%$ as compared to the European bloc. Thus, we can speak about a relatively similar standard of living in the two countries (EUROSTAT, 2015).

\section{Data and Methods}

\section{Sample profile}

Overall, there were 542 participants in the study, Romanians and Bulgarians in equal proportion. $52 \%$ of the 542 respondents were male, $48 \%$ were female and $86 \%$ were not married. Of the 271 Romanian students, 135 were students at the Faculty of Administration and Business, and 136 were students at the Faculty of Medicine in Bucharest. Bulgarian students were selected similarly, i.e. 135 students from the Faculty 
of Business in Sofia and 136 students at the Faculty of Medicine in Sofia. Both students in the business faculties and students in medicine were in the second year, at bachelor level, with ages ranging between 19 and 22.

\section{Methodology}

Our research was carried out in two stages. During the first stage we tried to answer the first two questions, i.e. whether there are significant differences between the buying behavior of Romanian and Bulgarian students from an ethical point of view, and if there exist differences between the students of the two majors.

In order to gather information we designed a questionnaire which was submitted to a group of 271 students from the two capital cities - Bucharest and Sofia. Every student was asked to fill in the questionnaire containing 8 statements. The Likert scale was used, and the students who answered „Strongly Agree" got 5 points, those who answered "Agree" got 4 points and so on. Given the negative meaning of questions 3 and 4 , the scale was reverted for these, i.e. the students who answered "Strongly Agree" got 1 point, those who answered "Agree" got 2 points and so on. For every statement 4 results according to the four majors were calculated.

In order to see whether there are any significant differences between the ethical behavior of students from the Faculty of Business and the behavior of students from the Faculty of Medicine in both countries, we applied the $t$ (Student) test for differences between two means, for independent samples, assuming there are equal dispersions (variations). The F (Fisher) test proved that the samples were taken from populations with equal dispersions. The chosen significance level was 0.05 .

During the second stage we wanted to find out whether there are significant differences between the students' declared behavior and their real ethical behavior, caused by their family's income. Question 4 is correlated to this; with question 4 we wanted to identify the main excuses/pretexts students use when they want to justify their unethical buying behavior often noticed in shops.

To this end the students were presented three scenarios, imagined by researchers, and were asked to imagine they are in a store, about to make a decision with regard to the purchase of a certain product which was the topic of one of the three scenarios.

One scenario involved buying counterfeit products, one involved purchasing products manufactured under women/children exploitation conditions and the final scenario involved a product that was potentially harmful to the environment. Scenarios were rotated within each group of respondents (Eckhardt, G. M. et al, 2010).

Surprisingly, the students chose to express their intention of buying at least one "dubious" product, i.e. they would buy either a counterfeit product, or a product produced under improper working conditions by women or children from the third world, or a product harmful for the environment, using quite some "stories" in order to justify their option.

We called these answers "super-stories” because they explain the reasons for the differences between the students' declared behavior and their real one, obviously unethical. The "stories"/pretexts are common to both Romanian and Bulgarian students, irrespective of their major.

Then we grouped these 8 ,super-stories" into 3 categories: „super-stories" which mention the price as the determining factor in the purchase, irrespective of the origin of the products (PRICE); „super-stories” whose underlying principle is the fact that counterfeit products, those that contribute to the degradation of the environment or those produced through the exploitation of women and children represent a feature of 
developing countries and that, as long as the production of these products generates jobs, nothing else should matter (DEV). Finally, there are those „super-stories” according to which the government and public institutions should take measures and prevent the access of "dubious" products into the marketplace, which practically exonerates the individual from any responsibility (INST). The 8 „superstories" are presented in annex 2.

Then we tried to find out whether there is any association between the types of "superstory" used (the central element being the "price" factor, the "development" factor and the "institutional" factor) and the type of income the student had.

To this end, the data were grouped into 3 categories: students whose parents earn between 300 and 500 Euros, students whose income per family is between 500 and 700 Euros, and students whose family income is more than 700 Euros per month. The data were structured as contingence tables.

Test chi-square was then applied. It allows the evaluation of the significance of the differences among the sub-groups of the sample. Low values of the test mean concordance among the sub-groups, and high values mean discrepancy among the analyzed subgroups.

\section{Discussion and Results}

For all of the 8 statements of the questionnaire 4 results were calculated: one for the students from the Faculty of
Administration and Business from Bucharest (FAA-B), one for the students from the Faculty of Medicine in Bucharest (Med B), one for the students from the Faculty of Business in Sofia (Buss S) and one for the students from the Faculty of Medicine in Sofia (Med S). According to the data centralized in table 1 , one can notice that there are no significant differences between Romanian and Bulgarian students as to the ethical buying behavior. For this we used $t$ test (Student) for differences between two means, considering independent samples, assuming there are equal dispersions. The average result obtained for the students from the Business faculties from the two countries for the 8 statements was 2.89 for the Romanian students and 2.97 for the Bulgarian students. The applied $t$ test confirmed that the null hypothesis according to which there are no significant differences between the ethical behavior of Romanian and Bulgarian students from the Business faculties can be accepted ( $t_{\text {calculated }}=-0.4<1.76$ $=t_{\text {tabular }}$ and the value of $p$ is 0.34 ).

As for the students in Medicine, the average result obtained was 2.88 for the Romanian students and 2.97 for the Bulgarian students. The $t$ test also confirms that there are no significant differences between the ethical behavior of students in Medicine from the two countries $\left(\mathrm{t}_{\text {calculated }}=-0.51<1.76=\mathrm{t}_{\text {tabular, }}\right.$, and the value of $p$ is 0.30 ).

In both cases the number of degrees of freedom was 14, and the level of significance was 0.05 . 
Table 1 : Results of the $t$ test for Business and Medicine students in Romania and Bulgaria

\begin{tabular}{|c|c|c|c|c|}
\hline Item & FAA-B & Med B & Buss S & Med S \\
\hline 1 & 3,09 & 2,83 & 3,05 & 3,03 \\
\hline 2 & 3,54 & 3,15 & 3,19 & 2,86 \\
\hline 3 & 2,45 & 2,84 & 2,81 & 3,16 \\
\hline 4 & 2,34 & 2,70 & 2,82 & 2,59 \\
\hline 5 & 3,13 & 3,24 & 3,38 & 2,94 \\
\hline 6 & 2,37 & 2,54 & 2,61 & 2,36 \\
\hline 7 & 3,59 & 3,45 & 3,35 & 3,71 \\
\hline 8 & 2,61 & 2,35 & 2,60 & 2,24 \\
\hline Total & $\mathbf{2 3 , 1 2}$ & $\mathbf{2 3 , 1 0}$ & $\mathbf{2 3 , 8 1}$ & $\mathbf{2 2 , 8 7}$ \\
\hline Average & $\mathbf{2 , 8 9}$ & $\mathbf{2 , 8 8 7 5}$ & $\mathbf{2 , 9 7 6 2 5}$ & $\mathbf{2 , 8 5 8 7 5}$ \\
\hline
\end{tabular}

(Source: authors' own calculus)

The analysis of the data presented in table 1 also supports the idea that there are no significant differences between the students of the two majors either, in both countries. As regards the Romanian students, the average result obtained for the 8 statements was 2.89 for the Faculty of Business and Administration (FAA -B) and 2.8875 for the Faculty of Medicine (Med B), i.e. practically equal results. The applied t test confirmed the null hypothesis according to which there are no significant differences between the ethical behavior of the students from the two majors in Romania $\left(t_{\text {calculated }}=0.011<1.76=\right.$ $t_{\text {tabular }}$ and the value of $p$ is 0.49 ).

As regards the Bulgarian students, the average result obtained was 2.97 for the students from the Faculty of Business (Buss S) and 2.85 for the Faculty of Medicine (Med
S) from Sofia. The $t$ test also confirmed that there are no significant differences between the ethical behavior of the students from the two majors $\left(t_{\text {calculated }}=0.14<1.76=t_{\text {tabular, }}\right.$ and the value of $p$ is 0.44 ).

In both cases, the number of degrees of freedom was 14, and the level of significance was 0.05 .

From the analysis of the data gathered one can notice that there are associations between the group of income to which the student belongs and the pretext used by that student in order to justify his/her unethical consumption behavior in both countries.

For this the following $3 \times 3$ contingency tables were

used:

Table 2: Romanian students' super-stories and the family's income

\begin{tabular}{|l|r|r|r|r|}
\hline & \multicolumn{1}{|l|}{ PRICE } & INST & DEV & Total RO \\
\hline $300-500$ & 45 & 18 & 27 & 90 \\
\hline $500-700$ & 9 & 6 & 3 & 18 \\
\hline $700-$ & 3 & 9 & 7 & 19 \\
\hline Total & $\mathbf{5 7}$ & $\mathbf{3 3}$ & $\mathbf{3 7}$ & $\mathbf{1 2 7}$ \\
\hline
\end{tabular}

(Source: authors' own calculus) 
The analysis technique used was the $\chi 2$ test. For 4 degrees of freedom and a level of significance of 0.05 , the tabulated value of $\chi 2$ is 9.48 , and the calculated one is 10.24 . Since $\chi 2$ calculated $>\chi 2$ tabulated, the null hypothesis according to which there are no associations between the two variables (pretext and income) for Romanian students is rejected.

Table 3: Bulgarian students' super-stories and the family's income

\begin{tabular}{|l|r|r|r|r|}
\hline & \multicolumn{1}{|l|}{ PRICE } & \multicolumn{1}{l|}{ INST } & DEV & Total BG \\
\hline $300-500$ & 82 & 17 & 27 & 126 \\
\hline $500-700$ & 12 & 4 & 2 & 18 \\
\hline $700-$ & 5 & 8 & 11 & 24 \\
\hline Total & $\mathbf{9 9}$ & $\mathbf{2 9}$ & $\mathbf{4 0}$ & $\mathbf{1 6 8}$ \\
\hline
\end{tabular}

(Source: authors' own calculus)

As regards the Bulgarian students, for 4 degrees of freedom and a level of significance of 0.05 , the tabulated value of $\chi 2$ is 9.48 , and the calculated one is 57.44. Since $\chi 2$ calculated $>\chi 2$ tabulated, it is confirmed that there exist associations between the two variables, i.e. pretext and income (http://www. statisticssolutions.com/nonparametric-analysis-chi- square/). The association is nevertheless more obvious in the case of Bulgarian students.

In general, one can notice that the students whose parents have lower incomes are influenced in their buying decisions by the "Price" (PRICE) factor to a greater extent, then by the "Development" (DEV) factor and only lastly by the "Institutional" (INST) factor, both in Romania and in Bulgaria.

Students originating from families with high income in Romania are influenced, as consumers, firstly by the "Institutional" (INST) factor, then by the "Development" (DEV) factor and the "Price" (PRICE) factor. The students with high incomes from Bulgaria on the other hand, are influenced firstly by the "Development" (DEV) factor, then by the "Institutional" (INST) factor and lastly by the "Price" (PRICE) factor.

\section{Conclusions}

The theories of reasoned action (Fishbein, 1980) and planned behavior (Ajzen, 1985, 1991) have fundamentally changed the view that attitudes directly translate into behavior by introducing intentions as a crucial intervening stage. Much research across numerous ethical contexts has drawn on these theories to offer a better understanding of how consumers form intentions to act in an ethical way. Persistently, researchers have suggested and discussed the existence of an intention-behavior gap in ethical consumption (Hassan, L. M., Shiu, E., Shaw, D.J., 2016). Yet, the factors that influence the extent of this gap and its magnitude have not been systematically examined. We, therefore, contribute to the debate on the intentionbehavior gap: the findings of our exploratory research suggest that there is indeed a large gap between intention and behavior, at least in the case of university students.

On the other hand, literature on consumer ethics tends to focus on factors such as the environment, and treats other drivers of consumption decisions, such as family, as non-moral, less influencing factors (Heath, T., O'Malley, L., Heath, M., Story, V., 2016). We argue that this is based upon a view of consumer behavior as non-dilemmatic. By demonstrating the importance of context to 
consumption decisions, we highlight how such decisions are both complex and situated when students have to face real shopping situations.

Our research has some implications for those who study ethics in consumption behavior.

First of all, one can notice that there are more similarities than differences as regards the ethics of buying behavior of students from Romania and Bulgaria. According to our results, there are no significant differences between the ethical behavior of Romanian and Bulgarian students. Moreover, there are no significant differences between the two majors-Business and Medicine-either. From a more general perspective this could mean that there exist universal norms as regards important social issues, norms that the students know they should respect.

Regardless of the country of origin or the major, most students declared they had knowledge in ethics (they read the labels about the origin of the product and publications related to the conditions under which products were produced, they attend lectures on environmental issues), they avoided to serve the interests of unethical companies by refusing to buy "dubious products" and last but not least tried to turn from counterfeit products to original products, even though the former most frequently represented a bargain.

Yet the latter implication complicated matters considerably. The moral imperative of the act of purchasing seems to diminish a lot under concrete purchasing situations. According to the results of our study, the students' ethical behavior tends to become unethical, the moral intensity of the issue of purchasing a product which disregards the principles of ethics no longer being perceived as part of their own identity (own ego). To be more specific, the level of income of the families from which students originate takes its toll on the purchasing decision. This indicator of the standard of living practically distorts the way they make a choice.
When having to justify their choices when they buy products that go against ethical and responsible behavior, both Romanian and Bulgarian students use pretexts, called „super-stories” by us, which practically question their declared convictions. When inside a store, students from families with low incomes prefer to buy the cheapest products, in most cases, regardless of the conditions under which they were produced. On the other hand, students whose parents have higher incomes prefer to attribute their unethical behavior to certain factors that exonerate them of their responsibility: the government (who does not prevent the proliferation of dubious products) and capitalism (which makes the exploitation of women and children seem normal, as a price paid on the road to development).

Under these circumstances, theoretical education, information and students' efforts to behave ethically as consumers seem to be strongly undermined by the reality of the standard of living, expressed by means of the family's income.

Our research has a number of limitations/weaknesses which do not allow the generalization of the results.

First of all, the number of students in the sample was limited both in Romania and in Bulgaria.

Secondly, we limited the number of statements regarding the ethical buying behavior to 8 .

Despite all these, these limitations included, we discovered aspects that can have a profound impact on the way corporations can evaluate their clients.

Firstly, our research shows that young consumers, students especially, are vulnerable and prone to equivocal behavior when faced with the situation of having to make a decision with regard to the purchase of products. Their behavior is the more equivocal (the more unethical) the lower 
their families' incomes are (the lower their standard of living is).

Secondly, there exists a generalized tendency of using pretexts (super-stories) when students are out shopping. The unethical behavior has the tendency of manifesting itself in a real way, despite the fact that Romanian and Bulgarian students prove to have the information and the knowledge necessary to discriminate between original products and products that disregard ethical and moral norms.

Even though every „super-story” indicated by the respondents is different, when considered together, these suggest a discouraging situation as to the wide, daily adaptation of ethical consumption.

The difference between "statement" and "deed", between "theory" and "practice" or between "intention" and "action" amongst young consumers can create confusion for the managers of companies producing original products, who will thus feel more threatened by the proliferation of dubious products which are sometimes extremely tempting to consumers. Maybe managers should identify more convincing strategies for turning customers more loyal to their products, with accent on their advantages as compared to the "dubious" products. The creation of products of high quality, sold at attractive prices could prove extremely useful so that the difference in terms of the original product's superiority to annihilate the one created by the price when it comes to the counterfeit/harmful product produced in sweatshops. The way socially responsible companies can induce an ethical behavior amongst consumers can be expressed on the one hand by the favoring of positive buying behavior (to buy only products created under conditions that observe ethical and moral norms, to ensure equitable commercialization from both the consumer's and the seller's perspectives etc.) through marketing campaigns, and on the other hand by inducing the idea of a moral imperative as a necessity associated to every act of consumption.

Finally, education has an essential role: that of discovering the instruments necessary to attenuate the impact of social and economical factors on the ethical buying and consumption behavior. Assuming that during the coming years economic development will allow a substantial increase in the standard of living for ever larger categories of population, the debate about the ethics of consumer behavior and the mentality related to it, which characterizes the new generation of educated young people, is still open .

\section{References}

- Ajzen, I. (1991), 'The Theory of Planned Behavior', Organizational Behavior and Human Decision Processes, 50, 179-211.

- Ajzen, I. (1985). 'From Intentions to Actions: A Theory of Planned Behavior'. Action Control: From Cognition to Behavior, Kuhl, J. and Beckman, J. (Eds). New York: Springer-Verlag, 11-39.

- Antil, J. H. (1984), 'Socially Responsible Consumers: Profiles and Implications for Public Policy', Journal of Macromarketing 4(Fall), 18-39.

- Auger, P. et al. (2003), 'What Will Consumers Pay for Social Product Features?' Journal of Business Ethics, 42(3), 281-384.

- Auger, P., Devinney, T. M. (2007), 'Do What Consumers Say Matter? The Misalignment of Preferences with Unconstrained Ethical Intentions', Journal of Business Ethics 76, 361-383.

- Ballantine, P. (2000). Examining the effects of culture on perceptions of moral intensity. Proceedings of the ANZMAC Visionary Marketing for the 21st Century Conference, 56-60. [Online]. ANZMAC [Retrieved May 15, 2016]. http://smib.vuw.ac.nz:8081/www/ANZMAC 2000/CDsite/papers 
- Belk, R. W. (1985), 'Issues in the Intention Behavior Discrepancy', Research in Consumer Behavior, vol. I, J. N. Sheth (ed), JAI Press: Greenwich, CT, 1-34.

- Bloch, P. H., Bush, R. F., Campbell, L. (1993), 'Consumer Accomplices in Product Counterfeiting: A Demand-Side Investigation', Journal of Consumer Marketing, 10(4), 27-36.

- Boulstridge, E., Carrigan, M. (2000), 'Do Consumers Really Care About Corporate Responsibility? Highlighting the AttitudeBehavior Gap', Journal of Communication Management, 4(4), 355-368.

- Carrigan, M., Attala, A. (2001), 'The Myth of the Ethical Consumer: Do Ethics Matter in Purchase Behavior?', Journal of Consumer Marketing, 18(7), 560-577.

- Cowe, R. \& Williams, S. (2001). 'Who are the ethical consumers? Parts 1 and 2'. [Online]. Co-operative Bank UK. [Retrieved June 5, 2016]. http://www.co_operativebank.co.uk

- Crane, A., Matten, D. (2004), Business Ethics: A European Perspective: Managing Corporate Citizenship and Sustainability in the Age of Globalization, Oxford University Press: Oxford.

- Creyer, E. H., Ross, W. T. (1997), The Influence of Firm Behavior on Purchase Intention: Do Consumers Really Care About Business Ethics?', Journal of Consumer Marketing, 14(6), 421-433.

- Davis, R. M. (1979), 'Comparison of Consumer Acceptance of Rights and Responsibilities', Proceedings, 25th Annual Conference of the ACCI, N. M. Ackerman (ed), 68-70.

- DePaulo, P. J. (1987), 'Ethical Perceptions of Deceptive Bargaining Tactics Used by Salespersons and Consumers. A Double Standard', Proceedings of the Division of
Consumer Psychology, J. G. Saegert (ed), 201203.

- Devinney, T. M., Auger, P., Eckhardt, G. (2010), The Myth of the Ethical Consumer, Cambridge University Press: Cambridge.

- Dodge, H. R., Kerch, K. B., Fullerton, S. (1996), 'Consumer Ethics: An Assessment of Individual Behavior in the Market Place', Journal of Business Ethics, 15(7), 805-814.

- Eckhardt, G. M., Belk, R., Devinney, T. M. (2010), 'Why Don't Consumers Consume Ethically?', Journal of Consumer Behavior, no. 9, 426-436.

- Elliott, K. A., Freeman, R. B. (2001), 'White Hats or Don Quixotes? Human Rights Vigilantes in the Global Economy', National Bureau for Economic Research (8102), Cambridge, M. A.

- EUROSTAT (2010), Europe in figures: Eurostat Yearbook 2010, European Union, 31-43.

- EUROSTAT (2015), Key figures on Europe. 2015 edition, European Union, 86. [Online] EU [Retrieved May 24, 2016] http://ec.europa.eu/eurostat/documents/32 17494/7072644/KS-EI-15-001-ENN.pdf/318ee884-50d6-48f0-b0864410da85d6b6

- Fishbein, M. (1980). Theory of Reasoned Action: Some Applications and Implications. Howe, H. \& Page, M (Eds), Nebraska Symposium on Motivation, 1979. Lincoln: University of Nebraska Press, 65-116.

- Fukukawa, K. (2002). 'Understanding Ethically Questionable Behavior in Consumption'. Journal of Business Ethics, 41(1), 99-119.

- Gail, T., Garibaldi, B., Zeng, Y., Pilcher, J. (1998), ,Consumer Demand for Counterfeit Goods', Journal of Psychology and Marketing, 15(5), 405-421. 
- Grove, S. J., Vitell, S. J., Strutton, D. (1989), 'Non-Normative Consumer Behavior and the Techniques of Neutralization', Proceedings of the 1989 AMA Winter Educators' Conference, R. Bagozzi and J. P. Peters (eds.).

- Haldeman, V. A., Peters, J. M., Tripple, P. A. (1987), 'Measuring a Consumer Energy Conservation Ethic: An Analysis of Components', Journal of Consumer Affairs, 21 (No. 1), 70-85.

- Hassan, L. M., Shiu, E., Shaw, D.J. (2016), 'Who Says There Is An Intention-Behavior Gap? Assessing the Empirical Evidence of An Intention-Behavior Gap in Ethical Consumption', Journal of Business Ethics, 136(2), 219-236.

- Heath, T., O'Malley, L., Heath, M., Story, V. (2016), 'Caring and Conflicted: Mothers' Ethical Judgments about Consumption', Journal of Business Ethics, 136(2), 237-250.

- Hunt, S. D., Vitell, S. (1992). 'The General Theory of Marketing Ethics: A Retrospective and Revision'. Ethics in Marketing, Quelch, J. \& Smith, C. (Eds). Chicago: Irwin.

- Hunt, S. D., Vitell, S. 'A General Theory of Marketing Ethics: A Revision and Three Questions'. (1986). Journal of Macromarketing, 6 (Spring), 5-15.

- Izzo, G. (1997), A theoretical perspective of the effects of moral intensity on consumers' ethical judgments of marketers non-normative methods. [Online]. University of Central Arkansas [Retrieved May 17, 2016] http://www.sbaer.uca.edu/research

- Jones, T.M. (1991), 'Ethical Decision Making by Individuals In Organizations: An Issue-Contingent Model', Academy of Management Review, 16, 366-395.

- Kallis, M. J., Krentier, K. A., Vanier, D. J. (1986), 'The Value of User Image in Quelling Aberrant Consumer Behavior', Journal of the Academy of Marketing Science, 14 (Spring), 29-35.
- Mason, T. (2000), 'The Importance of Being Ethical', Marketing 26, October, 27.

- McGregor, S. L. T. (2005), 'Sustainable Consumer Empowerment through Critical Consumer Education: A Typology of Consumer Education Approaches', International Journal of Consumer Studies, 29(5), 437-447.

- McGregor, S. L. T. (2007), 'Consumerism, the Common Good and the Human Condition', Journal of Family and Consumer Sciences, 99(3), 15-21.

- McShane, S. and Travaglione, T. (2005), Organizational Behavior on the Pacific Rim. New York: McGraw Hill.

- Moisander, J. (1998), 'Motivation for Ecologically Oriented Consumer Behavior'. [Online] Lancaster University [Retrieved June 3 , http://www.lancs.ac.uk/users/scistud/esf 2016]

- Moschis, G. P., Powell, J. (1986), 'The Juvenile Shoplifter', The Marketing Mix, 10 (Winter-Spring), 1-14.

- O'Shaughnessy. (1987). Why People Buy?. Oxford University Press: New York.

- Rogers, D. (1998), 'Ethical Tactics Arouse Public Doubt', Marketing (August 6), 12-13.

- Schwartz, S. H. (1977), 'Normative influences on altruism', Advances in Experimental Social Psychology, vol. 10, L. Berkowitz (Ed.), New York: Academic Press, 221-270.

- Simon, F. L. (1995), 'Global Corporate Philanthropy: A Strategic Framework', International Marketing Review, 12(4), 20-37.

- Stampfl, R. W. (1979), 'Multi-Disciplinary Foundations for a Consumer Code of Ethics', Proceeding of 25th Annual Conference of the American Council on Consumer Interests, N. M. Ackerman (ed.), 12-20. 
- Statistic Solutions (2016). Chi-Square Test of Independence. [Online] Statistic Solutions. [Retrieved August 15, 2016] http://www.statisticssolutions.com/nonparametric-analysis-chi-square/

- Sykes, G. M., Matza, D. (1957), 'Techniques of Neutralization: A Theory of Delinquency', American Sociological Review, 22 (Dec.), 664670.

- Ulrich, P., Sarasin, C. (1995), Facing Public Interest: The Ethical Challenge to Business Policy and Corporate Communications, Kluwer: London.
- Vitell, S. J., Muncy, J. (1992), 'Consumer Ethics: An Empirical Investigation of Factors Influencing Ethical Judgments of the Final Consumer', Journal of Business Ethics, 11 (Aug), 585-597.

- Wilkes, R. E. (1978), 'Fraudulent Consumer Behavior', Journal of Marketing, 42(Oct.), 67-75. 